Article

\title{
Monitoring of the 2011 Super Algal Bloom in Indian River Lagoon, FL, USA, Using MERIS
}

\section{Andrew Kamerosky ${ }^{1, \dagger}$, Hyun Jung Cho ${ }^{1, *, \dagger}$ and Lori Morris ${ }^{2}$}

1 Department of Integrated Environmental Science, Bethune-Cookman University, 640 Dr. Mary McLeod Bethune Boulevard, Daytona Beach, FL 32114, USA;

E-Mail: Andrew.Kamerosky@cookman.edu

2 St. Johns River Water Management District, PO Box 1429, Palatka, FL 32178, USA; E-Mail: 1morris@sjrwmd.com

$\dagger$ These authors contributed equally to this work.

* Author to whom correspondence should be addressed; E-Mail: choh@cookman.edu; Tel.:+1-386-481-2793.

Academic Editors: Deepak Mishra and Prasad S. Thenkabail

Received: 6 December 2014 / Accepted: 23 January 2015 / Published: 29 January 2015

Abstract: During the spring of 2011 an unprecedented "Super" algal bloom formed in the Indian River Lagoon (IRL), with Chlorophyll $a(\mathrm{Chl} a$ ) concentrations over eight times the historical mean in some areas and lasted for seven months across the IRL. The European Space Agency's MEdium Resolution Imaging Spectrometer (MERIS) platform provided multispectral data at 665 and $708 \mathrm{~nm}$, which was used to quantify the phytoplankton Chl $a$ by fluorescence while minimizing the effects of other water column constituents. The three objectives were to: (1) calibrate and validate two $\mathrm{Chl} a$ algorithms using all available MERIS data of the IRL from 2002 to 2012; (2) determine the accuracy of the algorithms estimation of Chl $a$ before, during, and after the 2011 super bloom; and (3) map the 2011 algal bloom using the Chl $a$ algorithm that was proven to be effective in other similar estuaries. The chosen algorithm, Normalized Difference Chlorophyll Index (NDCI), was positively correlated with the in-situ measurements, with an $\mathrm{R}^{2}$ value of 0.798 . While there was a significant $(62.9 \pm 25 \%)$ underestimation of Chl $a$ using MERIS NDCI, the underestimation appears to be consistent across the data and mostly in the estimations of lower concentrations, suggesting that a qualitative or ratio analysis is still valid. Analysis of the application of the NDCI processed MERIS data provided additional insights that the in-situ 
measurements were unable to record. The time series MERIS Chl $a$ maps along with in-situ water quality monitoring data depicted that the 2011 IRL bloom started after a heavy rainfall in March 2011 and peaked in October 2011 after a decrease in temperature. The bloom collapse also coincided with heavy rainfall and rapidly decreasing temperatures and salinity through October to November 2011.

Keywords: Chlorophyll $a(\mathrm{Chl} a)$; satellite remote sensing; MEdium Resolution Imaging Spectrometer; algal bloom; Indian River Lagoon

\section{Introduction}

Remote sensing of phytoplankton abundance and distribution in coastal waters has relied on algorithms to estimate Chlorophyll $a(\mathrm{Chl} a)$, a pigment responsible for the conversion of solar energy for photosynthesis found in all photosynthesizing life forms [1]. While there are accessory pigments such as Chlorophyll $b$ and Carotenoids, they have a considerably smaller impact in multi-spectral remote sensing [2]. Chl $a$ preferentially absorbs energy in the blue and red wavelengths $[3,4]$, which results in a relatively high reflectance in the green wavelength [5]. Chl $a$ also fluoresces in the Near InfraRed (NIR) near $700 \mathrm{~nm}$ during photosynthesis [6,7].

Most of the existing satellite data products and algorithms focus on the blue and green spectra, which are more suited for the less complicated open ocean [8]. However, remote sensing of Chl $a$ in Case 2 coastal surface water is more complicated compared to open ocean remote sensing because of several factors: absorption by Colored Dissolved Organic Matter (CDOM) [9]; turbidity from non-organic and organic total suspended solids (TSS) [10]; backscattering from shallow benthic vegetation such as submerged aquatic vegetation (SAV) [11]; and benthic substrates that create significant noise in upwelling energy $[1,12]$. CDOM strongly absorbs in the blue part of the visible spectrum $[9,13]$. TSS strongly reflect in the red spectrum and induce backscattering in the blue spectrum [14,15]. Incident light may be able to reach the bottom and the reflection can be included in the composite upwelling spectral profile from the water surface if the water clarity is high and water depth is shallow [16]. SAV, as with any other vascular, photosynthetic plants, absorbs Photosynthetically Active Radiation (PAR), reflects Near InfraRed (NIR), and therefore further alters the reflectance of the water [17,18]. The blue and green spectra can be impacted by Case 2 waters due to higher amounts of CDOM; and Chl $a$ can be examined with fewer complications through examining the red spectrum.

The MEdium Resolution Imaging Spectrometer (MERIS) package, aboard the European Space Agency (ESA) Environmental Satellite (ENVISAT), launched in March 2002 and provided a solution for these confounding factors of coastal waters, until the end of its mission in April 2012. MERIS had an ideal spectral resolution for measuring Chl $a$ in Case 2 waters, having 15 spectral bands from 390 to $1040 \mathrm{~nm}$. MERIS data have spatial resolutions of $1.2 \mathrm{~km}$ for "Reduced Resolution (RR)" and $300 \mathrm{~m}$ for "Full Resolution (FR)" [19]. RR is an average of 16 FR pixels and is made available more rapidly than FR [20].

Gower et al. [7] built the first MERIS based algorithm for Chl $a$, the Maximum Chlorophyll $a$ Index (MCI), which was able to model and track changes in Chl $a$ concentrations between $0.1 \mathrm{mg} \cdot \mathrm{m}^{-3}$ and $19 \mathrm{mg} \cdot \mathrm{m}^{-3}$. This approach uses bands centered at 681,708 and $753 \mathrm{~nm}$, as these longer wavelength bands 
are minimally affected by CDOM. In addition, the effects from TSS and water are speculated to be similar in red and NIR wavelengths [21]. The most notable aspect of the MCI is the use of the $708 \mathrm{~nm}$ band which is centered over the Chl $a$ fluorescence. Gower et al. [8] found that while MERIS FR provided the best detail, the RR, when filtered to exclude land, was able to reduce noise generally at the expense of losing the ability to track small $(<300 \mathrm{~m})$ blooms. Atmospheric correction resulted in less accurate reports as most atmospheric correction methods were not designed with the Chl $a$ fluorescence peak in mind and subsequently overcorrected the red and NIR spectrums in areas of high Chl $a$ concentrations [8]. Additionally, this algorithm is cautioned to be used as qualitative and was discouraged from use for estimating concentrations of Chl $a$ [22]. As a result of the MCI, several Chl $a$ algorithms have been developed that utilize the MERIS $708 \mathrm{~nm}$ bands in an effort to estimate Chl $a$ concentrations utilizing FR reflectance data.

Dall'Olmo and Gitelson [23] developed a three-band approach using bands 665, 708 and $753 \mathrm{~nm}$. They chose $665 \mathrm{~nm}$ because $681 \mathrm{~nm}$ was believed to be influenced by the fluorescence of Chl $a$. Their primary assumption with this model assumes that TSS affects all three bands equally. Moses et al. [24,25] (Referred to as Moses in this paper) proposed returning to a two band ratio between 665 and $708 \mathrm{~nm}$, due to the high rates of variability in three spectral points models. Mishra and Mishra [21] built the two band Normalized Difference Chlorophyll Index (NDCI) in an effort to improve models proposed by Moses et al. [25]. The NDCI uses 665 and $708 \mathrm{~nm}$ and operates similarly to the Normalized Difference Vegetative Index (NDVI) binding higher and lower index values between -1 and 1 and reducing seasonal variability and sun angle influences. A comparison of the NDCI effectiveness in Case 2 waters of the Chesapeake and Delaware Bays found NDCI was the most effective model, followed by Moses et al. [25] and then by Dall'Olmo and Gitelson [23] (Table 1). In a further effort to test the effectiveness of these algorithms for estuarine algal bloom mapping, we chose Moses et al. [25] and NDCI [21] to calibrate and validate $\mathrm{Chl} a$ in the Indian River Lagoon (IRL), FL a shallow estuary in which severe algal blooms have occurred in recent years

Table 1. Comparison of MERIS Chl $a$ estimation algorithms (Adapted from Mishra and Mishra [21]). Dall'Olmo and Gitelson [23] studied the Chesapeake Bay, USA; Moses et al. [24] studied the Sea of Azov; Mishra [21] studied Chesapeake, Delaware, and Mobile Bays and the Mississippi Delta, USA.

\begin{tabular}{cccc}
\hline Method & Algorithm & $\mathbf{R}^{2}$ & RMSE $\left(\mathbf{m g} \cdot \mathbf{m}^{-3}\right)$ \\
\hline Dall'Olmo and Gitelson [24] & $\frac{R_{753 \mathrm{~nm}}}{R_{665 \mathrm{~nm}}+R_{708 \mathrm{~nm}}}$ & 0.43 & 3.09 \\
\hline Moses et al., 2009 [25] & $\frac{R_{708 \mathrm{~nm}}}{R_{665 \mathrm{~nm}}}$ & 0.59 & 2.57 \\
\hline Mishra 2011 [22] & $\frac{R_{708 \mathrm{~nm}}-R_{665 \mathrm{~nm}}}{R_{708 \mathrm{~nm}}+R_{665 \mathrm{~nm}}}$ & 0.72 & 2.15 \\
\hline
\end{tabular}

Starting in the spring of 2011, an unprecedented algal bloom occurred in Indian River Lagoon (IRL), FL, which lasted for seven months throughout the IRL system (SJRWMD 2012). During the blooms, the mean Chl $a$ was eight times the historical mean concentration $\left(>50 \mu \mathrm{g} \cdot \mathrm{L}^{-1}\right.$ in most segments), which 
reduced light penetration through the water column and subsequently caused decreases in the density and distributions of SAV by up to $90 \%$ in some parts of the IRL [26].

The St. Johns River Water Management District (SJRWMD), the state regulatory body for the IRL, has been monitoring water quality monthly at 56 sites in the IRL since 1996 to support total maximum daily load (TMDL) development and general ecosystem health analysis. Thirty four of these sites are located on the IRL and another 22 on the tributaries to the IRL. TMDL is a pollution reduction and regulatory method used in an effort to identify the maximum amount of nutrients, metals, and organic compounds a water body can receive while still meeting water quality standards [27]. At "the historically normal conditions," the IRL has an average Chl $a$ concentration range from 6.2 to $16.4 \mu \mathrm{g} \cdot \mathrm{L}^{-1}$ [26], with seasonal algal blooms at $\mathrm{Chl} a$ levels reaching $25 \mu \mathrm{g} \cdot \mathrm{L}^{-1}$. The long-term field water quality monitoring data at the multiple sites, however, were not sufficient to show spatially continuous information because the surface water area of the IRL is $750 \mathrm{~km}^{2}$, meaning each monthly sampling site is used to assess an area of roughly $18 \mathrm{~km}^{2}$ [27]. Without spatially continuous visualization it was difficult to determine the spatial pattern of the bloom initiation, movement, and diminishment through the IRL.

This study was conducted to visually analyze the 2011 algal bloom (SJRWMD 2012) event that occurred in the IRL system at a landscape scale utilizing MERIS satellite-based Chl $a$ algorithms in order to provide additional information such as the bloom initiation, its progress and spatial expansion, and patterns of collapse. The three specific objectives were to (1) evaluate the NDCI and Moses using MERIS RR to determine the accuracy of the algorithms in estimation of Chl $a$ in IRL, (2) map the 2011 algal bloom by using the algorithm that suggests to be most effective, and (3) provide spatially continuous visual analysis of the 2011 algal bloom to compare with in-situ water quality measurements.

\section{Methods}

\subsection{Study Area}

The Indian River Lagoon (IRL) is a $252 \mathrm{~km}$ estuarine system along the east coast of central Florida, USA (UTM $17 \mathrm{~N} 28.568^{\circ} \mathrm{N}, 80.757^{\circ} \mathrm{W}$; Figure 1) with the average depths ranging from 0.8 to $1.8 \mathrm{~m}$ and widths varying from 0.5 to $5 \mathrm{~km}$ [27]. The IRL provides critical habitat for several dozen commercially and recreationally important fisheries valued at one billion dollars a year [28] and has one of the most diverse seagrass communities within the United States [29]. It also provides habitat to several endangered species such as Florida manatee (Trichechus manatus latirostris] [29]. In addition to seagrass, there are other types of submerged aquatic vegetation (SAV) such as drifting and benthic macroalgae throughout the IRL [30].

The IRL is divided into three sub-lagoons; Mosquito Lagoon (ML), the IRL proper, and Banana River (BR) (Figure 1), as each of these sections has unique water residence times, ecology, chemistry, and watershed development [26]. The IRL proper is further divided into two sections; North (NIRL) and South (SIRL). NIRL is then subdivided into North-North IRL (N-NIRL) and Central-North IRL (C-NIRL).

ML is a marine portion of the IRL with a mean salinity of 32 Practical Salinity Units (PSU), is fed by a largely undeveloped watershed, has large beds of predominately Halodule wrightii (Shoalgrass) and Syringodium filiforme (Manateegrass), and has a large population of clams, mussels, oysters, and other filter feeders [31]. N-NIRL is similar to ML, sharing a water residence period of around a year. C-NIRL 
has an average of 18.7 PSU, receives an average of more than three times higher runoff rates compared to N-NIRL, and has a shorter residence period of around 100 days [30]. BR shares similar salinity means with C-NIRL, but has an intermittent connection to the ocean through a canal-lock facility at Port Canaveral and has the longest residence time of the entire IRL ( $>1$ year) [30]. Unlike the rest of the system, SIRL has access to the ocean via inlets, which result in mean salinities around 28 PSU, very short residence, and less lagoon-like qualities. The SIRL is also too narrow for the effective use MERIS RR images; and is excluded from this study.

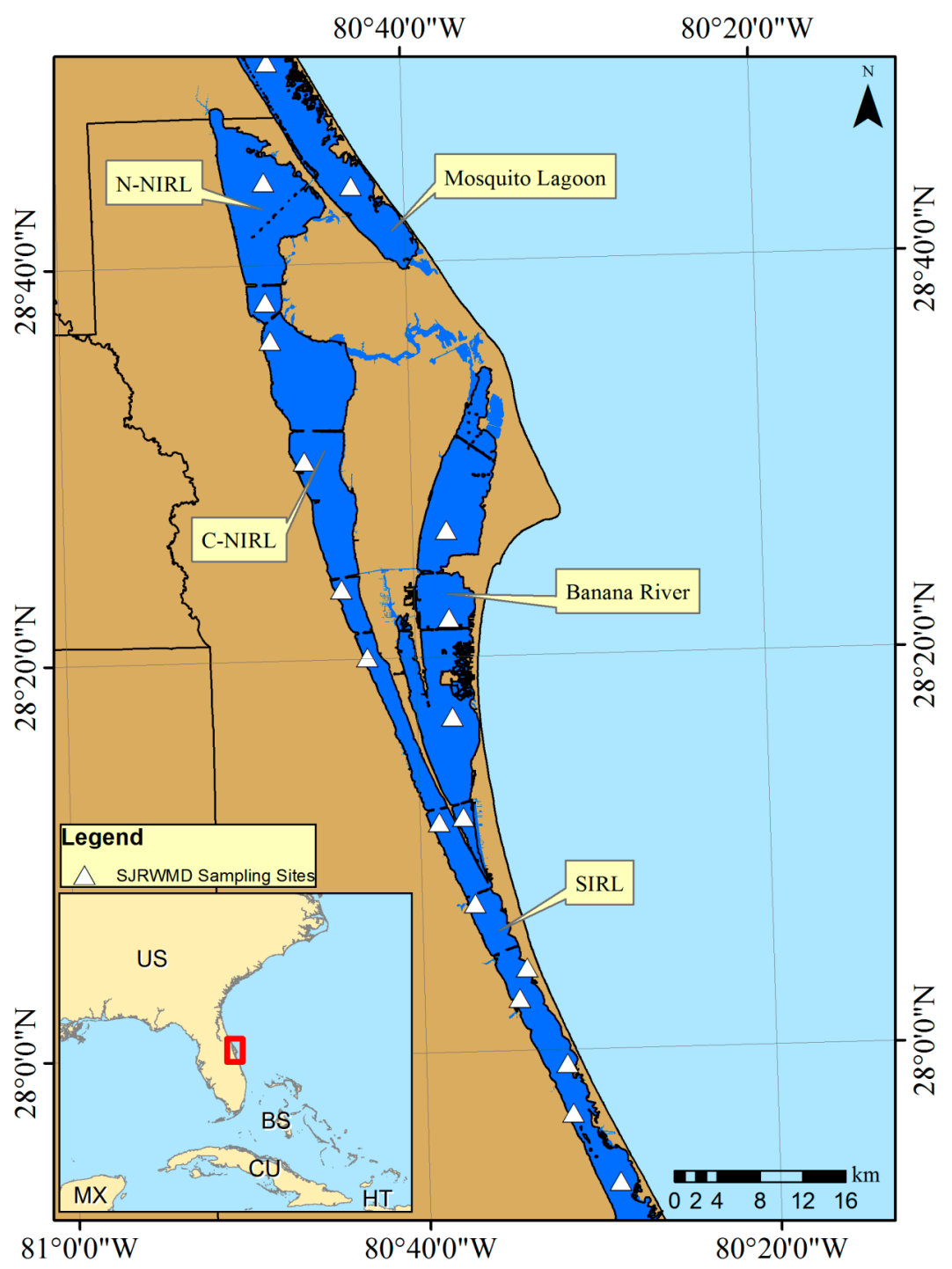

Figure 1. Map of Indian River Lagoon (IRL), FL. The IRL is divided into Mosquito Lagoon, North-Northern IRL (N-NIRL), Central-NIRL (NIRL), Banana River, and Southern IRL (SIRL). The St. John's River Water Management District (SJRWMD) monthly surface water monitoring sites in the Indian River Lagoon (IRL), FL used in this study for algorithm calibration are indicated by triangles. The inset indicates the IRL's location in relation to State of Florida. 


\subsection{MERIS Data Acquisition and Preprocessing}

All MERIS data were obtained via the European Space Agency's (ESA) On Demand Restricted Data Access program. Through the ESA MERIS Catalogue and Inventory (MERCI) service, an initial number of 238 scenes were obtained in L1. The L1 MERIS dataset is Top of the Atmosphere (ToA) Radiance; the data have been radiometrically and geometrically corrected to the units of $10^{-3} \mathrm{~W} \cdot \mathrm{m}^{-2} \cdot \mathrm{sr}^{-1} \cdot \mathrm{nm}^{-1}$. The scenes for the 2011 algal bloom analysis encompass those that fell on the same day as the SJRMWD field sampling days from May 2002 to the end of the MERIS mission in April 2012.

In this study L1 MERIS data were chosen instead of atmospherically corrected remote sensing reflectance L2 MERIS data that was used in the previous studies [21,24,25] because our preliminary analysis of the L2 data showed weak correlations with the corresponding field monitoring data when using either Moses $\left(\mathrm{R}^{2}=0.019\right)$ or NDCI $\left(\mathrm{R}^{2}=0.012\right)$. Moses et al. [25] suggested that atmospheric correction may negatively influence the Chl $a$ signal in highly turbid, shallow waters. The IRL system is shallower (depths of 1.5-3 m) than the coastal systems used in previous studies by Moses et al. [25] and Mishra and Mishra [22]. The Azov Sea and Delaware Bay used by Moses [24,27] had average depths of $9 \mathrm{~m}$ and 2.5-10 m, respectably [32] and 6-30 $\mathrm{m}$ in the Chesapeake Bay used by Mishra and Mishra [33].

In order to calibrate the algorithms, the entire history of MERIS dataset was considered. Out of 426 SJRWMD field sampling days from May 2002 to April 2012, 170 sampling days occurred when ENVISAT was not on station or made a night pass, 137 when the MERIS scene covered only a portion of the IRL, and 106 when there was cloud covers over the IRL sampling sites. There were only thirteen days when samples were taken with no cloud cover over sampling sites with at least one per year (Table 2). The scenes were georeferenced into World Geodetic System (WGS) 1984, projected into Florida State Plane by the Georeference MERIS tool in the Exelis ENVI 5.0 ${ }^{\circledR}$ (Boulder, CO, USA), and checked for cloud cover and any data flags generated by ESA for erroneous data. Band 13 (band center at $865 \mathrm{~nm}$ ), which is used for atmospheric correction by the ESA, was used to create a cloud mask using ENVI.

Locations for known seagrass beds were obtained from the SJRWMD Geographic Information System (GIS) Database and used to select out sampling sites that were over seagrass [34] because the seagrass beds may affect algorithm estimation of water column phytoplankton Chl $a$. Spectral profiles of all pixels that contained the sampling locations were extracted and examined to ensure that the values were not impacted by land or seagrass beds (Figure 2). There were a total of 50 pixels where field sampled Chl $a$ values could be related to remotely sensed values (Table 2).

Table 2. The dates and number of MERIS dataset used in the study to compare with SJRWMD in-situ data from 2002 to 2013.

\begin{tabular}{cccc}
\hline Date & Number of Samples & Date & Number of Samples \\
\hline $11 / 12 / 2003$ & 6 & $1 / 8 / 2009$ & 2 \\
$11 / 8 / 2004$ & 1 & $3 / 3 / 2009$ & 3 \\
$9 / 13 / 2005$ & 2 & $3 / 4 / 2010$ & 4 \\
$1 / 9 / 2006$ & 5 & $4 / 7 / 2010$ & 2 \\
$1 / 12 / 2006$ & 6 & $5 / 9 / 2011$ & 4 \\
$12 / 3 / 2007$ & 7 & $1 / 4 / 2012$ & 1 \\
$12 / 3 / 2008$ & 7 & & \\
\hline
\end{tabular}




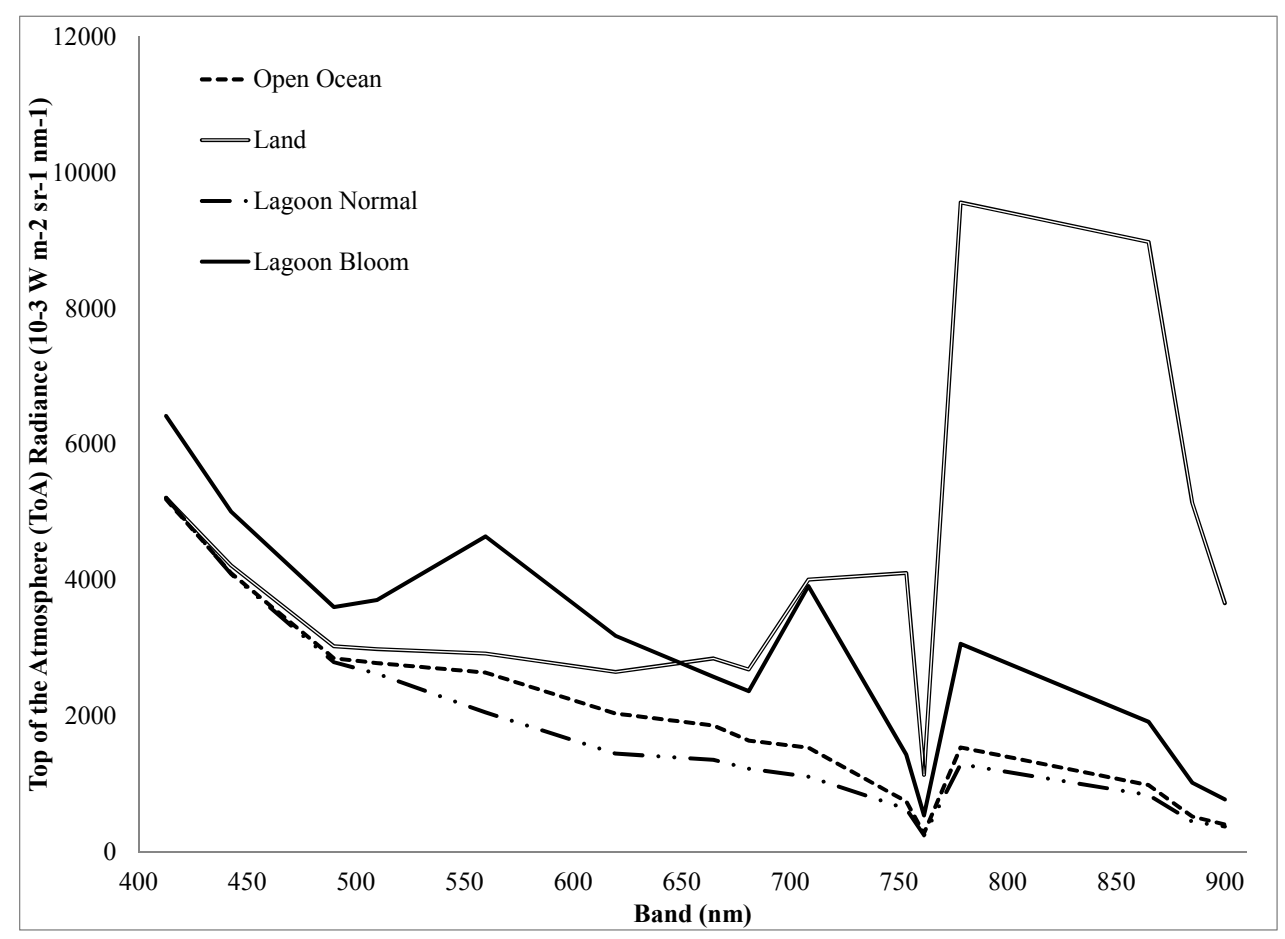

Figure 2. Representative MERIS spectral profiles of open ocean (Atlantic Ocean), land, normal conditions in the lagoon, and algal bloom conditions in the lagoon.

\subsection{In-Situ Water Quality and Ancillary Data}

Water quality data including Chl $a$, turbidity, TSS, CDOM, water depth, salinity and water temperature collected monthly from 1996 to 2013 at 19 lagoon stations out of the 34 SJRWMD IRL sample sites (Figure 1) were obtained from SJRWMD. The water quality data were collected the first week of every month. Salinity and temperature were measured by a HACH Hydrolab MS5 (Loveland, $\mathrm{CO}$ ); and Chl $a$, TSS, and turbidity were measured in accordance with Environmental Protection Agency (EPA) methods and laboratory protocols [27].

Additional data sources were used to provide water quality conditions between the SJRWMD's monthly sampling dates. There is one United States Geological Survey (USGS) water monitoring station located between ML and N-NIRL, the USGS 02248380 Haulover Canal monitoring station $\left(28^{\circ} 44^{\prime} 10^{\prime \prime}\right.$, $80^{\circ} 45^{\prime} 18^{\prime \prime}$ ), which provided water temperature data through the USGS National Water Information System [35]. For lagoon-wide spatially continuous water temperature, MODIS-certified water temperature maps were obtained from NASA's Ocean Color data distribution service [36] and processed through Exelis ENVI 5. Weather data, including air temperature and precipitation, were obtained from the National Oceanographic and Atmospheric Administration's (NOAA) National Weather Service Forecast Melbourne, FL Office [37] and NOAA Quality Controlled Local Climatological Data (QCLD) program [38]. 


\section{Data Analysis}

\subsection{MERIS Chl a Index Calculation}

The 50 MERIS L1 ToA Radiance pixel values were used to calculate the NDCI and Moses values. The algorithm processed MERIS data were exported into the statistical software SPSS 17.0 (IBM Corporation Armonk, NY, USA) and regressed with the SJRWMD field monitored Chl $a$ concentration values to generate a line of best fit that can be used for converting algorithm values to estimated Chl $a$. Accuracies of the two algorithms were tested using Standard Error of Estimate (STE), and coefficient of determination $\left(\mathrm{R}^{2}\right)$ with confounding bio-optical factors (Chl a TSS, turbidity, and depth). All statistical significance was evaluated at an $\alpha$ of 0.05 .

\subsection{MERIS Chl a Index Assessments with Field Data}

There were 10 additional MERIS scenes not used for index calculation between January 2011 and December 2011 that coincided with SJRWMD sampling days because of cloud covers or partial coverage of the IRL. These images were used for algorithm validation. There were 40 pixels in these scenes that coincided with the in-situ samples that were not flagged for cloud or atmospheric interference by the ESA. The coinciding pixel values were converted by the NDCI and Moses using the ENVI Band Math tool. The resulting values were then used to validate estimated Chl $a$ concentrations calculated by the calibrated algorithms. For the two estimated datasets, one for NDCI and the other for Moses, Root Mean Square Error (RMSE) and average percent error to the field data were calculated.

\subsection{Algal Bloom Mapping Using MERIS Chl a Index}

From January 2011 to March 2012, there were a total of 22 scenes that had at least two of the four IRL segments free of clouds, but did not coincide with SJRWMD sampling days. These maps were exported into ESRI's ArcMap 10.1 (Redlands, CA, USA) in GeoTIFF format for visualization and analysis. To display time series movement of the 2011 algal bloom, the MERIS data were converted into estimated Chl $a$ using the Chl $a$ algorithm that was proven to be more effective after comparing the NDCI and Moses index performances. The Zonal Statistics tool of ArcMap 10.1 was used to determine the mean and standard deviation of the estimated Chl $a$ for each of the four IRL sub lagoons; ML, N-NIRL, C-NIRL, and BR.

\section{Results and Discussion}

\subsection{Algorithm Assessment}

\subsubsection{MERIS Chl a Estimation Index Calibration}

The calibration equation for MERIS Moses index was: Chl $a=(42.72 \times$ Moses $)-32.03\left(\mathrm{R}^{2}=0.433\right.$, $p$ value $<0.001$, STE $5.292 \mu \mathrm{g} \cdot \mathrm{L}^{-1}$, Figure 3 ), while each of the optically cofounding variables such as depth, turbidity, and TSS, had low correlation coefficients with the algorithm values (Table 3). The calibration equation for MERIS NDCI index was: Chl $a=10.77+109.04 \times(\mathrm{NDCI})+286.00 \times(\mathrm{NDCI})^{2}$ 
$\left(\mathrm{R}^{2}=0.508, p\right.$ value $<0.001, \mathrm{STE}=4.941 \mu \mathrm{g} \cdot \mathrm{L}^{-1}$ (Figure 4) with depth, turbidity and TSS having similarly low correlation with the algorithm values (Table 3 ).

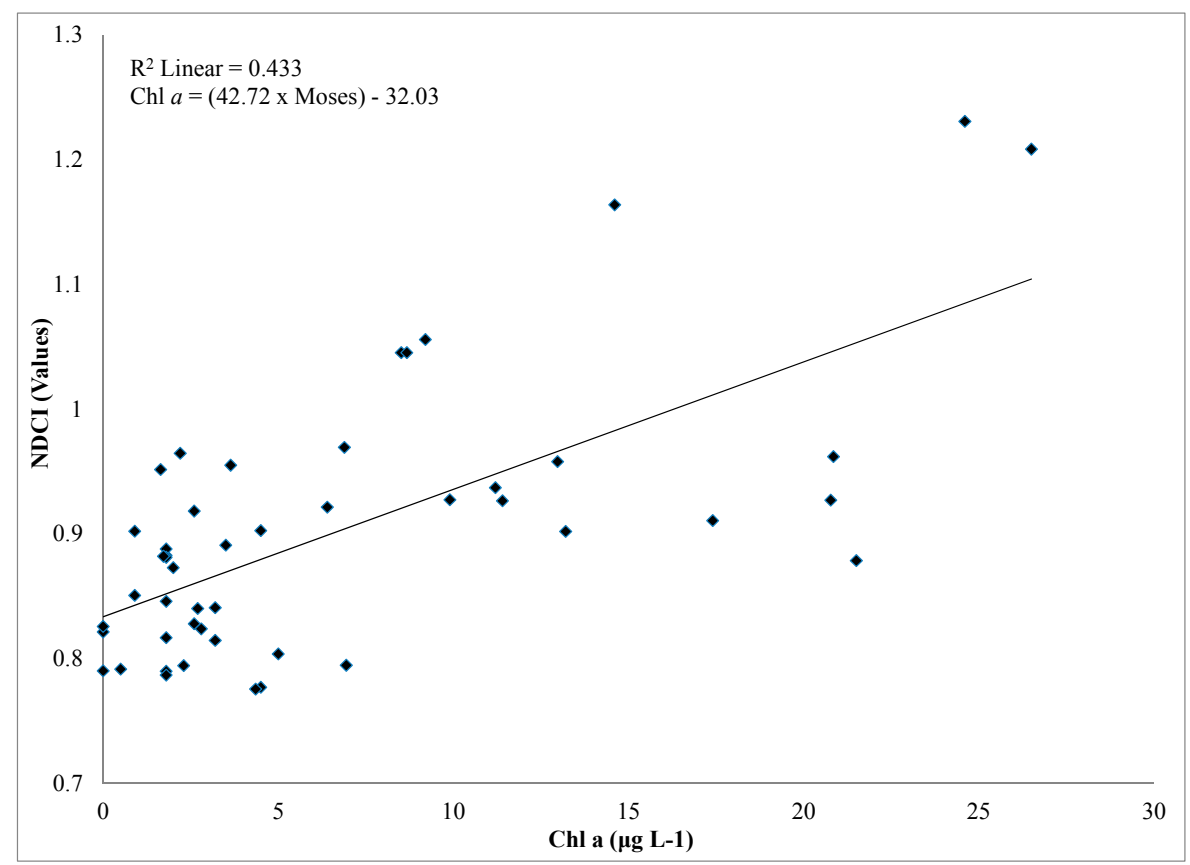

Figure 3. Regression analysis of in-situ $\mathrm{Chl} a$ measurements and their corresponding MERIS pixel data that has been converted by Moses. The produced line of best fit is used to convert the Moses values into estimated Chl $a$.

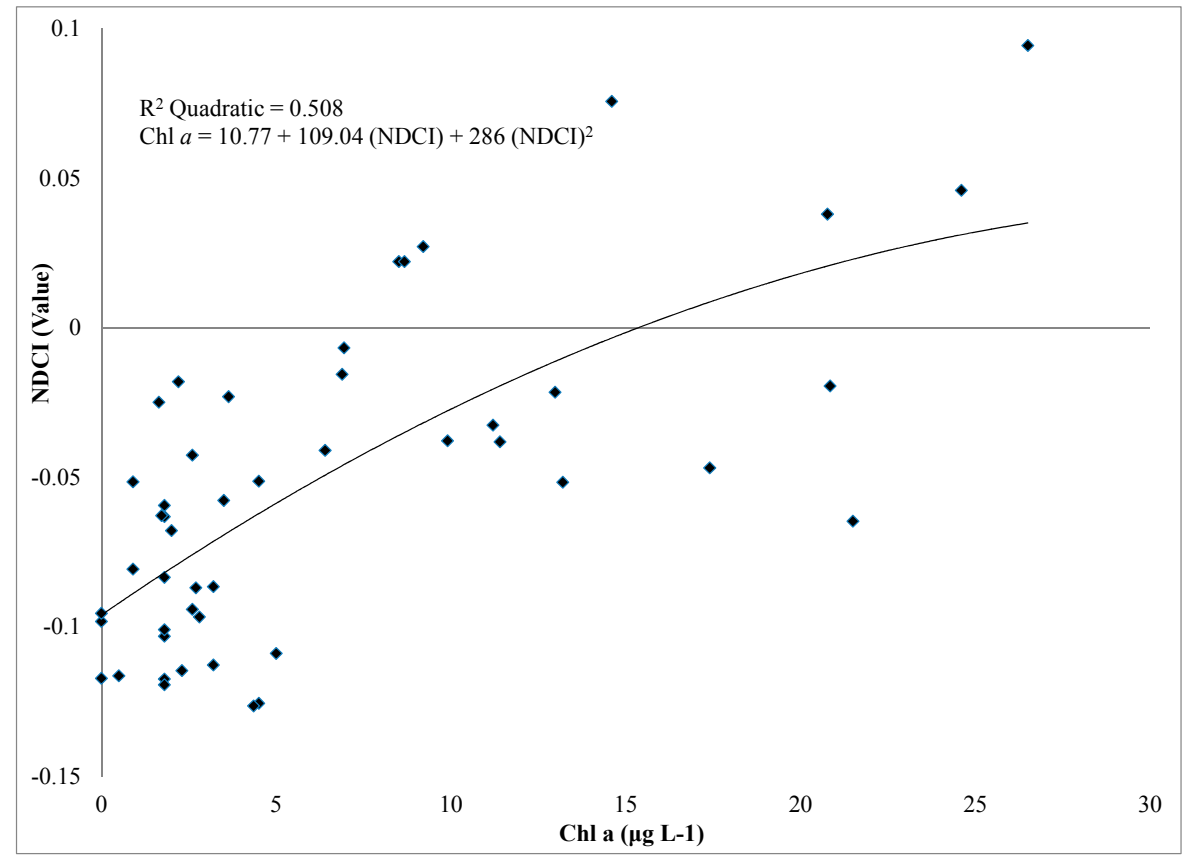

Figure 4. Regression analysis of in-situ $\mathrm{Chl} a$ measurements and their corresponding MERIS pixel data that has been converted by the NDCI algorithm. The resulting line of best fit is used to convert the NDCI values into estimated Chl $a$. 
Table 3. Coefficient of Determination $\left(\mathrm{R}^{2}\right)$ values between the index values of Moses and Normalized Difference Chlorophyll Index (NDCI) as well as each of the environmental factors Chl $a$, depth, turbidity, and TSS. * $p<0.5$.

\begin{tabular}{ccccc}
\hline Algorithm & Chl $\boldsymbol{a}$ & Depth & Turbidity & TSS \\
\hline Moses & $0.433 *$ & 0.058 & 0.015 & 0.058 \\
NDCI & $0.508 *$ & 0.027 & 0.001 & 0.038 \\
\hline
\end{tabular}

\subsubsection{MERIS L1 Chl $a$ Estimation Validation}

Results of accuracy analysis of NDCI and Moses in Chl $a$ estimation in IRL are presented in Table 4. NDCI algorithms underestimated the field monitored Chl $a$ by $62.9 \pm 25 \%$, whereas Moses underestimated by $118 \pm 180 \%$ (Table 4). As concentrations of in-situ $\mathrm{Chl} a$ increased, magnitudes the underestimation increased for the both algorithms. The RMSE for NDCI was $33.39 \mathrm{mg} \cdot \mathrm{L}^{-1}$ and for Moses $34.75 \mathrm{mg} \cdot \mathrm{L}^{-1}$. Despite the underestimation, the $\mathrm{R}^{2}$ between the estimated and in-situ value for NDCI was 0.80 and Moses had 0.69 (Table 4). Moses appeared not to be sensitive to the changes in Chl $a$ at low Chl $a$ concentrations; the algorithm values varied the most with $\mathrm{Chl} a$ when the highest concentrations $\left(80-100 \mu \mathrm{g} \cdot \mathrm{L}^{-1}\right)$ (Figure 5). As NDCI had the higher correlation and the most sensitivity to changes in Chl $a$, even at the low concentrations, it was chosen for the analysis of the 2011 algal bloom.

Table 4. Percent Error (\% Error), Root Mean Squared Error (RMSE), and Coefficient of Determination $\left(\mathrm{R}^{2}\right)$ values of NDCI and Moses estimated Chl $a$ to in-situ measurements.

\begin{tabular}{ccccc}
\hline Algorithm & $\mathbf{N}$ & \% Error & RMSE $\left(\boldsymbol{\mu g} \cdot \mathbf{L}^{-\mathbf{1}}\right)$ & $\mathbf{R}^{\mathbf{2}}$ \\
\hline NDCI & 40 & $-62.9 \pm 25 \%$ & 33.39 & 0.798 \\
Moses & 40 & $-118 \pm 180 \%$ & 34.75 & 0.686 \\
\hline
\end{tabular}

\subsubsection{MERIS NDCI and Moses Accuracy}

Using RR MERIS data, the NDCI and Moses were related to in-situ Chl $a$ values to evaluate the algorithms in estimation of Chl $a$ in the IRL system, FL. RR MERIS data had higher error values (RMSE of $33.39 \mu \mathrm{g} \cdot \mathrm{L}^{-1}$ for NDCI and $34.75 \mu \mathrm{g} \cdot \mathrm{L}^{-1}$ for Moses) and compared to the results by Mishra and Mishra [21] that used FR MERIS data (RMSE of $2.15 \mu \mathrm{g} \cdot \mathrm{L}^{-1}$ for NDCI and $2.57 \mu \mathrm{g} \cdot \mathrm{L}^{-1}$ for Moses). The large difference in percent error (Table 1) between the NDCI and Moses were probably attributed to the effects of normalization in NDCI which tends to make the index values saturated at high Chl $a$ values.

However, the in-situ data and NDCI-derived Chl $a$ concentrations had a statistically significant, positive correlation $\left(\mathrm{R}^{2}=0.68 ; p<0.001\right)$. This suggests a uniform underestimation; the temporal changes in Chl $a$ trend was similar when NDCI estimated values are compared to the in-situ values (Figure 6). Factors likely contributing to this underestimation are the following. (1) The limited range of $\mathrm{Chl} a$ in the assessment dataset with the highest $i n$-situ data of value $\left(26.5 \mu \mathrm{g} \cdot \mathrm{L}^{-1}\right)$ used to calibrate the algorithm (in comparison to values recorded as high as $122 \mu \mathrm{g} \cdot \mathrm{L}^{-1}$ outside of the dataset used for calibration). (2) The small number of sampling in the pixels (one per pixel). (3) the possible Chl $a$ variation within the given pixel as Moses et al. [21] observed. Moses et al. [21] identified that Chl $a$ fluorescence varied by as much as $35 \%$ over $1.2 \mathrm{~km}$, which means a single field sample per the reduced 
resolution MERIS pixel is not a sufficient representative of the sampling area and could result in over- or underestimation.

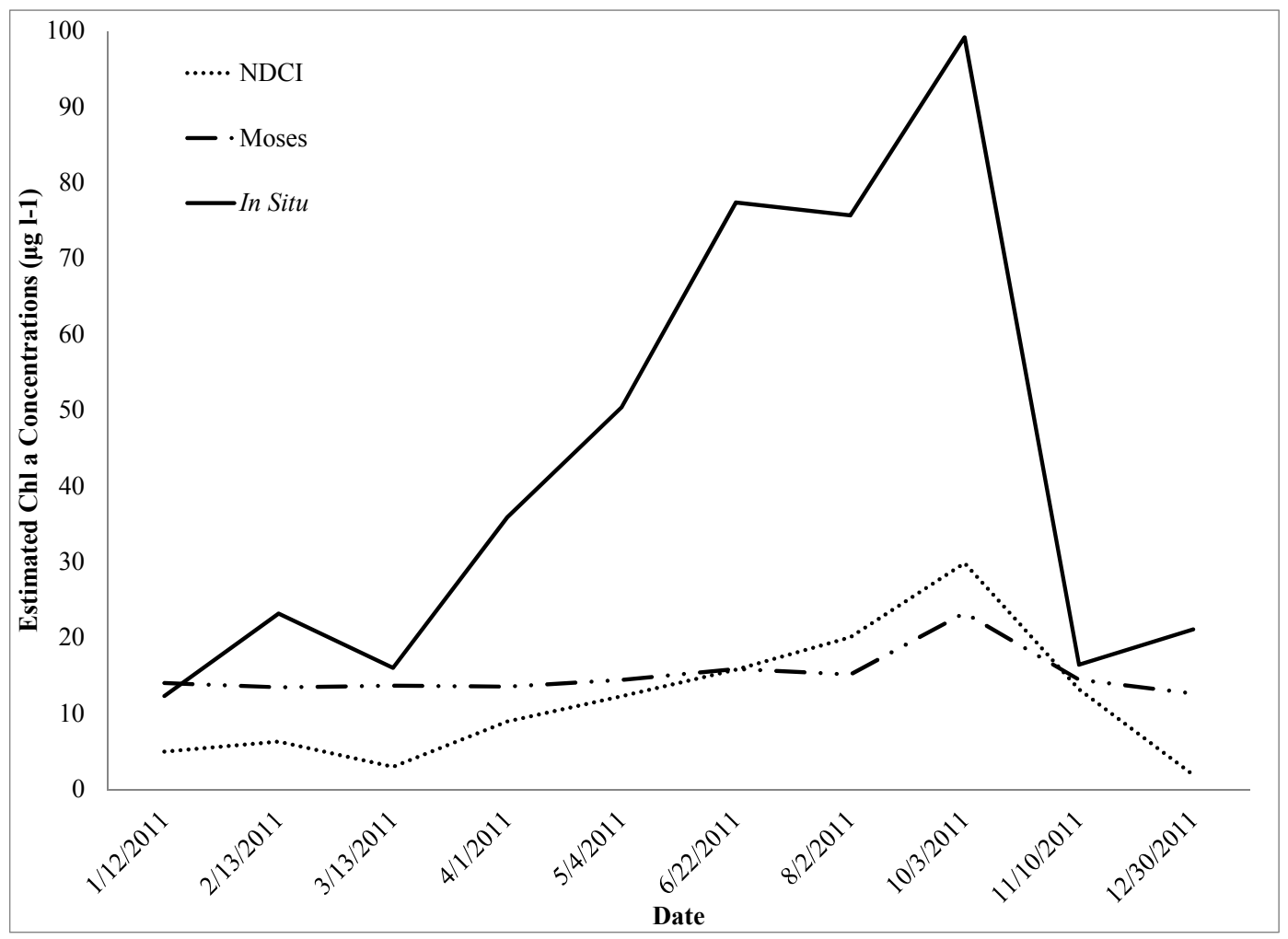

Figure 5. Comparison of the MERIS-estimated $\mathrm{Chl} a$ concentrations using the Normalized Difference Chlorophyll Index (NDCI) and Moses with in-situ measurements in Indian River Lagoon.

\subsection{In-situ Water Quality Monitoring Data}

The Indian River Lagoon had the highest and the most persistent recorded algal bloom in 2011 since 1996 when the SJRWMD started monitoring the IRL's Chl $a$ (Table 5). All statistics reported are significant at $p<0.01$. The mean in-situ Chl $a$ of the entire IRL during 2011 was $23.71 \pm 27 \mathrm{mg} \cdot \mathrm{L}^{-1}$ which was statistically significantly higher than the historical mean of $6.79 \pm 10 \mathrm{mg} \cdot \mathrm{L}^{-1}$ during the monitoring duration by SJRWMD. N-NIRL and BR exhibited the highest mean Chl $a$ concentrations in 2011 (43.83 \pm 41 and $41.49 \pm 33 \mathrm{mg} \cdot \mathrm{L}^{-1}$ respectively). The SIRL, the portion of IRL that was not used for MERIS analysis, exhibited the lowest mean concentration $\left(15.06 \pm 6 \mathrm{mg} \cdot \mathrm{L}^{-1}\right)$ (Table 5).

Mean salinity value throughout the IRL was higher during 2011 by 10 PSU when compared with the historical means (Table 5). Turbidity values were also higher in 2011, and more than doubled in several basins. Turbidity did not return to its historical conditions (historical mean $13.34 \pm 6$ NTU) in ML (Table 5). TSS, on the other hand, did not increase compared to the historical mean values, and all segments but ML had significant decreases in TSS in 2012. Phlips et al. [26] reported that both total nitrogen and phosphorus were almost double in 2011 than previous years and increased in step with growth of the bloom. 
Table 5. Descriptive statistics for the St Johns River Water Management District water quality data for the Indian River Lagoon. This table compares the 2011 Bloom with the historical averages (1996-2010) and post bloom (January-March 2012) conditions. Units for salinity, Total Suspended Solids (TSS), Turbidity, and Chlorophyll a (Chl $a$ ) are PSU, $\mathrm{mg} \cdot \mathrm{L}^{-1}$, NTU, and $\mu \mathrm{g} \cdot \mathrm{L}^{-1}$, respectively. The IRL is divided into North-Northern IRL (N-NIRL), Central-NIRL (NIRL), and Southern IRL (SIRL).

\begin{tabular}{lccc}
\hline Whole IRL & $\mathbf{1 9 9 6 - 2 0 1 0}$ & $\mathbf{2 0 1 1}$ & $\mathbf{2 0 1 2}$ \\
\hline Salinity & $25.82 \pm 5$ & $35.05 \pm 4$ & $32.74 \pm 4$ \\
TSS & $13.28 \pm 12$ & $13.92 \pm 9$ & $6.42 \pm 7$ \\
Turbidity & $4.85 \pm 4.84$ & $7.51 \pm 4$ & $4.13 \pm 5$ \\
Chl $a$ & $6.79 \pm 10$ & $23.7 \pm 27$ & $9.95 \pm 9$ \\
\hline ML & $\mathbf{1 9 9 6 - 2 0 1 0}$ & $\mathbf{2 0 1 1}$ & $\mathbf{2 0 1 2}$ \\
\hline Salinity & $33.13 \pm 5$ & $39.77 \pm 2$ & $39.69 \pm 1$ \\
TSS & $22.96 \pm 25$ & $15.91 \pm 6$ & $20.86 \pm 10$ \\
Turbidity & $5.75 \pm 6$ & $8.16 \pm 4$ & $13.34 \pm 6$ \\
Chl $a$ & $3.91 \pm 3$ & $26.22 \pm 29$ & $22.76 \pm 14$ \\
\hline BR & $\mathbf{1 9 9 6 - 2 0 1 0}$ & $\mathbf{2 0 1 1}$ & $\mathbf{2 0 1 2}$ \\
\hline Salinity & $22.46 \pm 4$ & $33.64 \pm 3$ & $31.86 \pm 2$ \\
TSS & $14.32 \pm 13$ & $16.83 \pm 9$ & $5.91 \pm 3$ \\
Turbidity & $4.65 \pm 4$ & $9.01 \pm 3$ & $3.51 \pm 1$ \\
Chl $a$ & $6.45 \pm 6$ & $41.49 \pm 34$ & $10.38 \pm 8$ \\
\hline N-NIRL & $\mathbf{1 9 9 6 - 2 0 1 0}$ & $\mathbf{2 0 1 1}$ & $\mathbf{2 0 1 2}$ \\
\hline Salinity & $28.09 \pm 5$ & $38.15 \pm 2$ & $37.37 \pm 2$ \\
TSS & $14.21 \pm 11$ & $16.16 \pm 7$ & $8.51 \pm 10$ \\
Turbidity & $3.73 \pm 4$ & $8.58 \pm 4$ & $6.71 \pm 7$ \\
Chl $a$ & $5.62 \pm 7$ & $43.83 \pm 41$ & $10.45 \pm 13$ \\
\hline C-NIRL & $\mathbf{1 9 9 6 - 2 0 1 0}$ & $\mathbf{2 0 1 1}$ & $\mathbf{2 0 1 2}$ \\
\hline Salinity & $22.8 \pm 4$ & $32.95 \pm 2$ & $31.81 \pm 2$ \\
TSS & $14.21 \pm 10$ & $14.32 \pm 6$ & $4.11 \pm 2$ \\
Turbidity & $4.54 \pm 4$ & $7.76 \pm 3$ & $2.72 \pm 1$ \\
Chl $a$ & $8.38 \pm 13$ & $29.91 \pm 22$ & $10.37 \pm 5$ \\
\hline SIRL & $\mathbf{1 9 9 6 - 2 0 1 0}$ & $\mathbf{2 0 1 1}$ & $\mathbf{2 0 1 2}$ \\
\hline Salinity & $22.61 \pm 6$ & $30.78 \pm 4$ & $29.35 \pm 2$ \\
TSS & $12.39 \pm 9$ & $13.76 \pm 7$ & $3.1 \pm 2$ \\
Turbidity & $3.71 \pm 4$ & $6.52 \pm 3$ & $1.44 \pm 1$ \\
Chl $a$ & $7.23 \pm 8$ & $15.06 \pm 6$ & $5.41 \pm 3$ \\
\hline & & & \\
\hline
\end{tabular}

\subsection{Algal Bloom Time Series MERIS Maps}

The MERIS NDCI maps during the 2011 algal bloom are presented in Figures 6 and 7; and the sublagoon mean values are shown in Figure 8 and listed in Table 6 . The noticeable increase in Chl $a$ occurred in BR between 13 March and 1 April, resulting in an increase from $4.5 \pm 1.5 \mu \mathrm{g} \cdot \mathrm{L}^{-1}$ (mean January-March) to a mean of $9.0 \mu \mathrm{g} \cdot \mathrm{L}^{-1}$ in April. C-NIRL began to show notable increases between 1 April and 4 May from a mean of $2.72 \pm 1.0 \mu \mathrm{g} \cdot \mathrm{L}^{-1}$ (December to April) to $8.8 \mu \mathrm{g} \cdot \mathrm{L}^{-1}$ in 4 May. N-NIRL 
Chl $a$ concentrations began to increase from a mean of $3.8 \pm 1.3 \mu \mathrm{g} \cdot \mathrm{L}^{-1}$ (January-March) to $7.2 \pm 1.1 \mu \mathrm{g} \cdot \mathrm{L}^{-1}$ between 31 May and 19 June. Chl $a$ values in ML rose above an average of $4.5 \pm 1.1 \mu \mathrm{g} \cdot \mathrm{L}^{-1}$ (mean January to July) to $8.4 \pm 1.4 \mu \mathrm{g} \cdot \mathrm{L}^{-1}$ between 31 May and $19 \mathrm{June}$, with a peak of $14.7 \mu \mathrm{g} \cdot \mathrm{L}^{-1}$ in $22 \mathrm{June}$.

The bloom event peaked on 3 October 2011 when values were the highest across the IRL for the year (Figures 7 and 8; and also refer to the map figures). Chl $a$ increased by $100 \%$ between 14 September and 3 October in the ML, N-NIRL, and C-NIRL, and by $50 \%$ in the BR during the same time period (Figure 8). Shortly thereafter, between 3 October and 14 October, all areas throughout the IRL exhibited declines in the NDCI estimated Chl $a$; $18 \%$ in ML, $11 \%$ in BR, 32\% in N-NIRL, and $22 \%$ in C-NIRL. There were further decreases in the NDCI values between 14 October and 23 October in the southern half of the IRL study area, by $46 \%$ and $50 \%$ in the C-NIRL and BR, respectively, while N-NIRL and ML exhibited no change in NDCI values. Northern IRL exhibited large decreases in Chl $a$ between 23 October and 10 November, by $61 \%$ and $54 \%$ in N-NIRL and ML, respectively (Figure 8). The IRL Chl $a$ conditions returned to historical means by 21 January 2012, except for ML which had an elevated Chl $a$ concentration of $9.7 \mu \mathrm{g} \cdot \mathrm{L}^{-1}$. This Chl $a$ elevation in ML could have been due to another algal bloom referred to as a Brown Tide that subsequently occurred in early 2012 and affected throughout the ML [26].

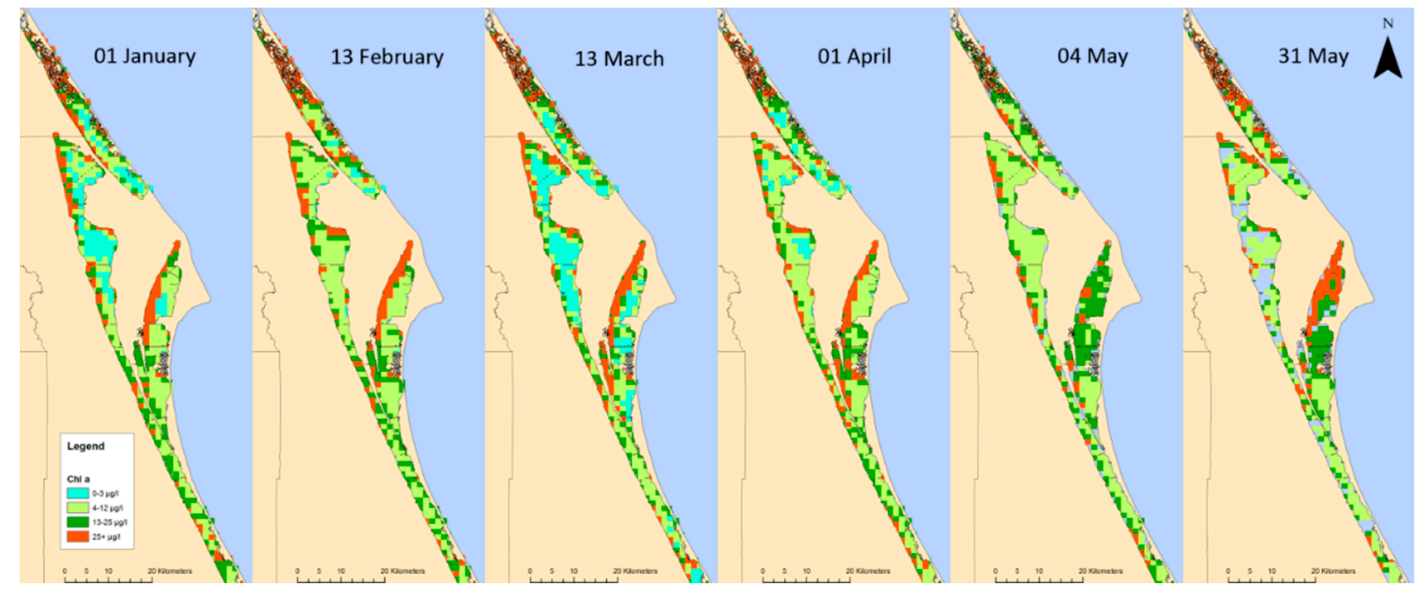

Figure 6. MERIS Normalized Difference Chlorophyll Index (NDCI) estimated Chlorophyll $a$ concentrations ( $\mathrm{Chl} a$ ) the period of the 2011 bloom initiation period.

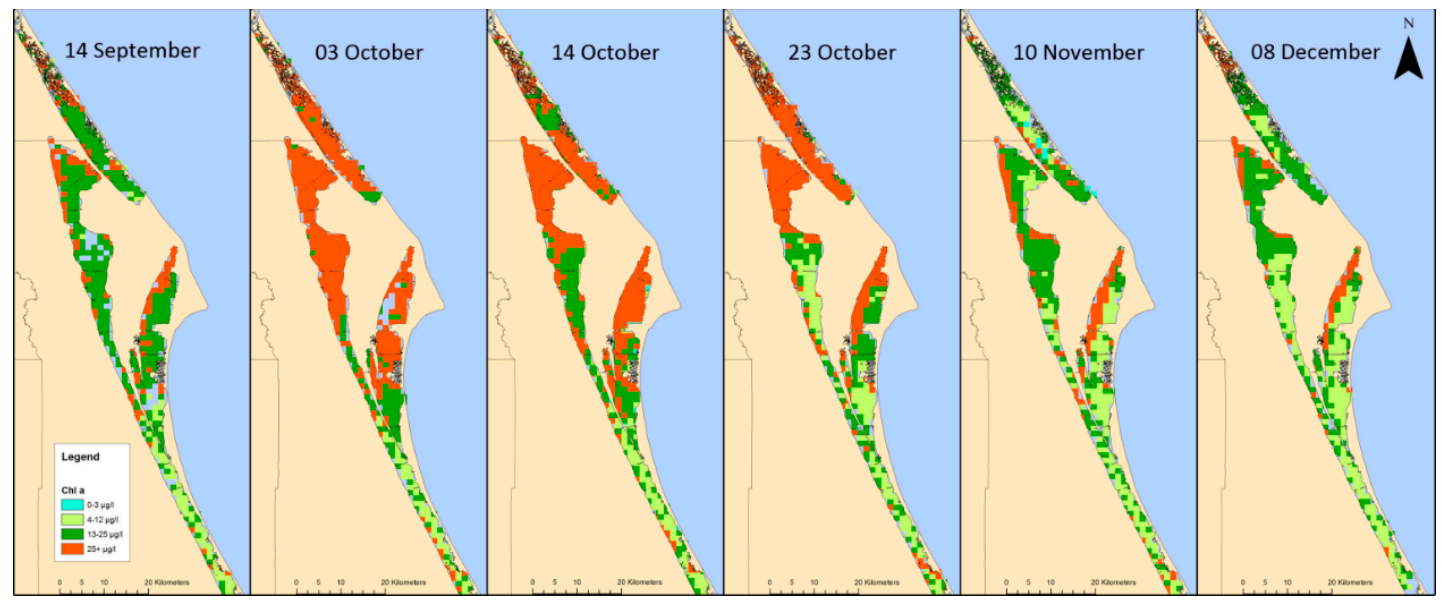

Figure 7. MERIS Normalized Difference Chlorophyll Index (NDCI) estimated Chlorophyll $a$ concentrations ( $\mathrm{Chl} a$ ) during the 2011 bloom collapse period. 


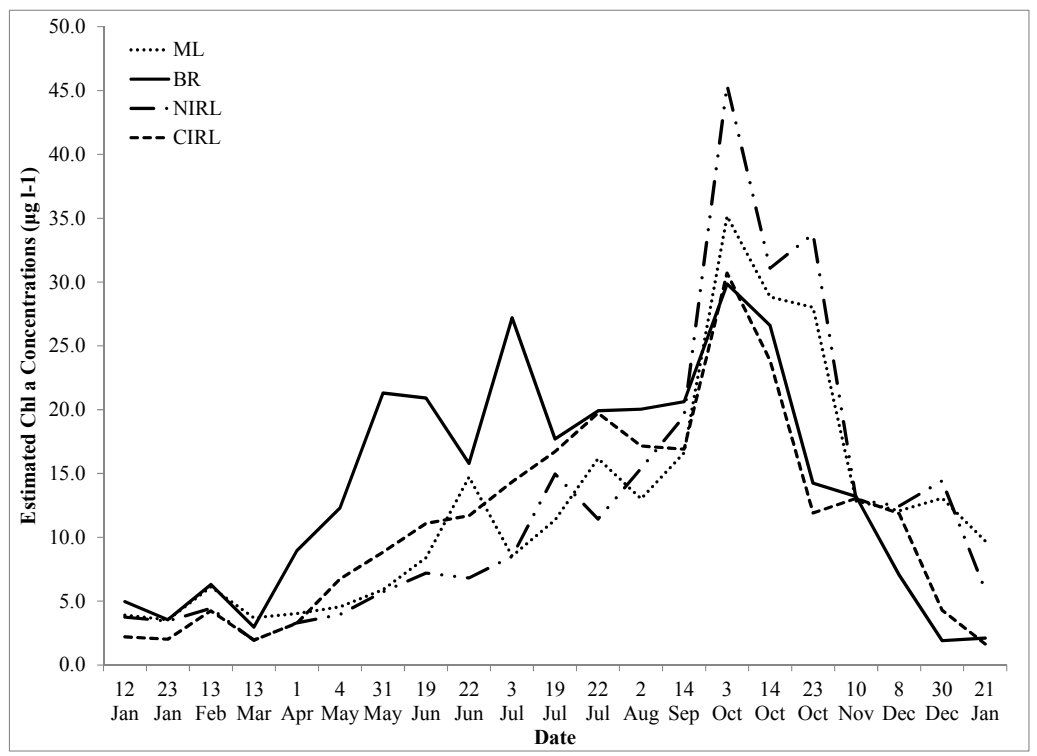

Figure 8. MERIS Normalized Difference Chlorophyll Index (NDCI) estimated Chl $a$ concentrations $\left(\mu \mathrm{g} \cdot \mathrm{L}^{-1}\right)$ from 12 January 2011 to 18 March 2011 for Indian River Lagoon Segments Mosquito Lagoon (ML), Northern North IRL (N-NIRL), Central North IRL (C-NIRL), and Banana River (BR).

Table 6. MERIS NDCI estimated Chlorophyll a concentrations $\left(\mu \mathrm{g} \cdot \mathrm{L}^{-1}\right)$ from 12 January 2011 to 18 March 2012 for Indian River Lagoon Segments Mosquito Lagoon (ML), Banana River (BR), Northern North IRL (N-NIRL), and Central North IRL (C-NIRL)

\begin{tabular}{ccccc}
\hline Date & ML & N-NIRL & C-NIRL & BR \\
\hline $1 / 12 / 2011$ & 3.9 & 3.7 & 2.2 & 5.0 \\
$1 / 23 / 2011$ & 3.5 & 3.4 & 2.0 & 3.5 \\
$2 / 13 / 2011$ & 6.1 & 4.4 & 4.2 & 6.3 \\
$3 / 13 / 2011$ & 3.7 & 1.9 & 1.9 & 3.0 \\
$4 / 1 / 2011$ & 4.0 & 3.3 & 3.3 & 9.0 \\
$5 / 4 / 2011$ & 4.6 & 3.9 & 6.7 & 12.3 \\
$5 / 31 / 2011$ & 5.9 & 5.7 & 8.8 & 21.3 \\
$6 / 19 / 2011$ & 8.4 & 7.2 & 11.1 & 20.9 \\
$6 / 22 / 2011$ & 14.7 & 6.8 & 11.7 & 15.8 \\
$7 / 3 / 2011$ & 8.5 & 8.5 & 14.3 & 27.2 \\
$7 / 19 / 2011$ & 11.4 & 15.0 & 16.7 & 17.7 \\
$7 / 22 / 2011$ & 16.2 & 11.4 & 19.7 & 19.9 \\
$8 / 2 / 2011$ & 13.0 & 15.4 & 17.2 & 20.0 \\
$9 / 14 / 2011$ & 16.6 & 19.5 & 16.9 & 20.6 \\
$10 / 3 / 2011$ & 35.2 & 45.4 & 30.7 & 29.8 \\
$10 / 14 / 2011$ & 28.8 & 31.1 & 23.9 & 26.6 \\
$10 / 23 / 2011$ & 28.0 & 33.8 & 11.9 & 14.2 \\
$11 / 10 / 2011$ & 12.8 & 13.0 & 13.1 & 13.2 \\
$12 / 8 / 2011$ & 12.1 & 12.4 & 11.9 & 7.1 \\
$12 / 30 / 2011$ & 13.1 & 14.4 & 4.3 & 1.9 \\
$1 / 21 / 2012$ & 9.7 & 5.9 & 1.6 & 2.1 \\
$3 / 18 / 2012$ & 10.7 & 1.7 & 3.9 & 10.5 \\
\hline & & & &
\end{tabular}




\subsection{Bloom Event Observed by MERIS Data and Ancillary Data}

According to our MERIS NDCI data, the 2011 algal bloom began between March and April 2011 in the Banana River (BR) (Figure 6). Water quality data collected by the SJRWMD supports our satellite data analysis (Figure 5) as $\mathrm{Chl} a$ concentrations doubled from $15.52 \mu \mathrm{g} \cdot \mathrm{L}^{-1}$ in March to $31.84 \mu \mathrm{g} \cdot \mathrm{L}^{-1}$ in April, then increased to $48.62 \mu \mathrm{g} \cdot \mathrm{L}^{-1}$ in May ( $3 \times$ of the March value). Field in-situ data further supported our satellite data analysis results that the bloom began in the BR based on monthly Chl $a$ samples collected by Philps et al. [39,40]. Heavy rains can increase nutrient levels in the IRL and are thought to be a trigger for previous algal blooms of picocyanobacteria and dinoflagellates in the summer months [39-41]. On 31 March 2011, there was $9.4 \mathrm{~cm}$ of rainfall recorded by the National Weather Service's Melbourne, FL Office (75\% of the combined historical monthly mean for both March and April), which could have helped to trigger the 2011 algal bloom. Salinity in BR did not change significantly between March and April (33.69 to 33.67 PSU) as measured by the SJRWMD, though there was an $8 \%$ decrease in conductivity from Haulover Canal over the course of 31 March 2011 rain event. Nitrogen measured by the SJRWMD increased from 0.55 to $2.99 \mathrm{mg} \cdot \mathrm{L}^{-1}$ and phosphorus from 0.09 to $0.18 \mathrm{mg} \cdot \mathrm{L}^{-1}$ between March and April, but these concentrations are not significantly different from their historical means since they had been decreasing in concentration over the past decade [30].

At the beginning of October 2011, the highest concentrations of Chl $a$ was observed both from the MERIS NDCI values (Figure 6) and from the in-situ values measured by SJRWMD throughout the IRL. Mean water temperatures recorded at the USGS Haulover Canal dropped from $29.4^{\circ} \mathrm{C}$ (30 September 2011) to $25.7^{\circ} \mathrm{C}$ (3 October 2011; Figure 9). While MODIS surface temperature maps were not available for this event, all IRL segments have similar temperature fluctuations [40,41]. The initial drop in temperature coincided with the peak of the bloom between 14 September and 3 October throughout the IRL (Figure 6).

The first decrease in Chl $a$ was detected 11 days after the peak, between 3 October and 14 October throughout the IRL and then between 14 October and 23 October (Figures 6 and 8). Between 3 October and 14 October we estimated a decrease in Chl $a$ values using the NDCI throughout the IRL (of 18\% in ML, $11 \%$ in BR, 32\% in N-NIRL, and 22\% in C-NIRL). A rain event totaling $16.5 \mathrm{~cm}$ occurred on 8 October and another storm on 9 October brought the monthly total to $26.7 \mathrm{~cm}$, which more than doubled the historical monthly average of $12.9 \mathrm{~cm}$. At the Haulover Canal station the specific conductivity decreased by $11.3 \%$ between 8 October and 10 October after the heavy rains. Mean water temperature increased from $23{ }^{\circ} \mathrm{C}$ to $27^{\circ} \mathrm{C}$ within two days after the storms. An initial drop in temp during the storm, was followed by rapid warming of 4 degrees $\mathrm{C}$ within 2 days may have disrupted the algal bloom and provided more favorable conditions for grazers to continue to reduce the bloom (Figure 9).

Between 14 October and 23 October the NDCI Chl $a$ values in the southern half of the IRL study area decreased, with the N-CIRL and BR decreased by $46 \%$ and 50\%, while N-NIRL and ML remained unchanged (Figures 7 and 8). Water temperature at Haulover Canal the next day dropped from a mean of $24{ }^{\circ} \mathrm{C}$ to $20.8^{\circ} \mathrm{C}$, along with estimated surface water temperatures throughout the IRL to a mean of $21{ }^{\circ} \mathrm{C}$ as estimated by MODIS. The earlier heavy rain events led to a reduced salinity from October (measured before the rain) to November (Figure 9). The SJRWMD measured salinity dropped between October to November from 37 to 31 PSU in the BR and 33 to 29 PSU in C-NIRL, while the N-NIRL and ML remained above 36 PSU. 


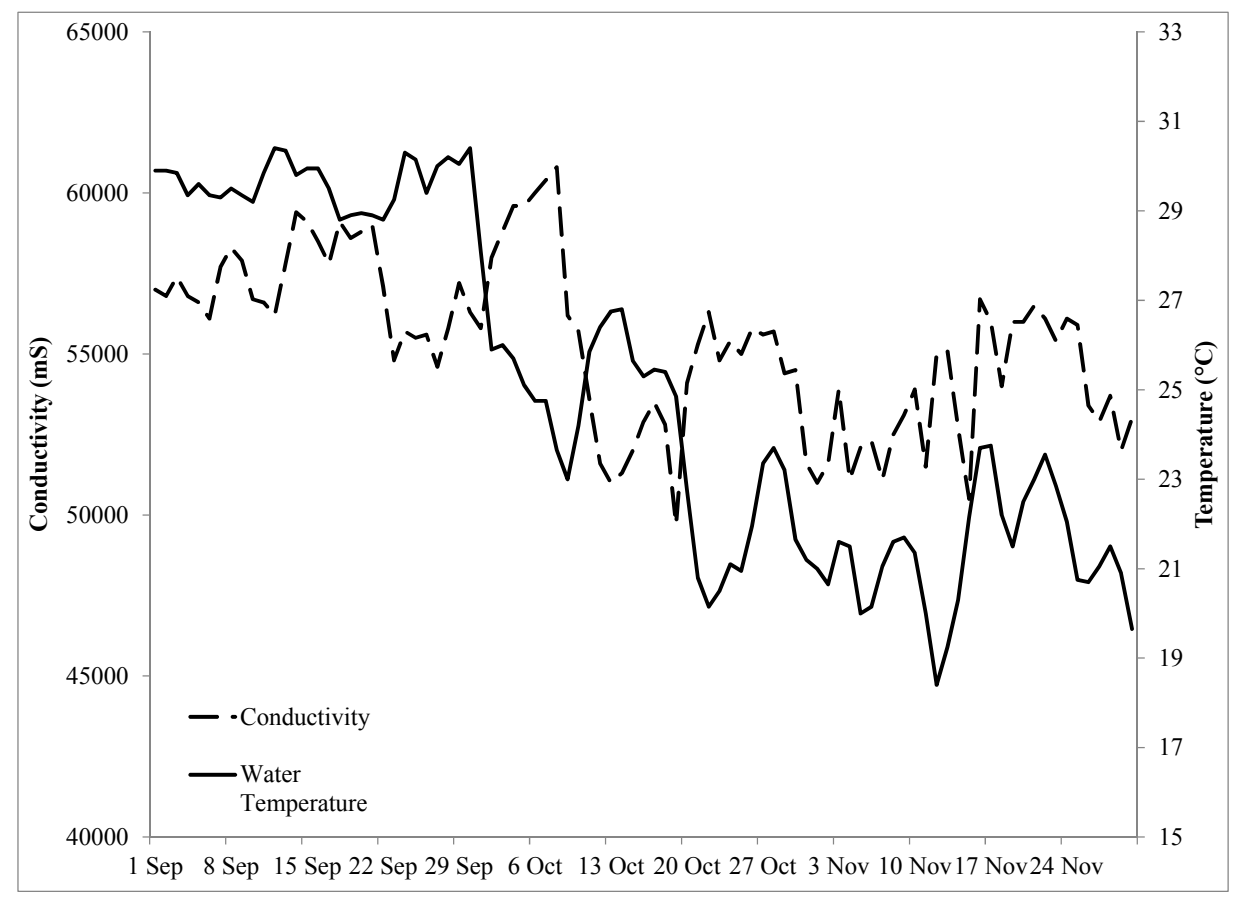

Figure 9. Conductivity and temperature measured at the Haulover Canal, FL USGS water station from September to November 2011.

Between 23 October and 10 November, the northern IRL had a large decrease in Chl $a, 61 \%$ in N-NIRL, and 54\% in ML, suggesting the end to most of the bloom conditions in the IRL (Figures 7 and 8). Water temperature dropped to $20^{\circ} \mathrm{C}$ from a high of $29.6{ }^{\circ} \mathrm{C}$ in the start of October 2011 . However Chl $a$ remained above its pre-bloom mean (Figure 6) in the northern sections, suggesting a remnant of the bloom was still occurring. By 8 December the BR returned to pre-bloom conditions $\left(7.1 \mu \mathrm{g} \cdot \mathrm{L}^{-1}\right)$, followed by C-NIRL by 30 December $\left(4.3 \mu \mathrm{g} \cdot \mathrm{L}^{-1}\right)$, and then N-NIRL on 21 January $2012\left(5.9 \mu \mathrm{g} \cdot \mathrm{L}^{-1}\right)$. ML, however, did not return to the pre-bloom conditions and maintained an increased $\mathrm{Chl} a$ concentration $\left(9.7 \mu \mathrm{g} \cdot \mathrm{L}^{-1}\right)$.

The uneven decrease in the bloom conditions (Figure 6) may have been due to different changes in salinity between the northern and southern parts of the IRL. The southern part of the IRL has lower residence times and mean salinity than the rest of the study area because it is located closer to ocean inlets and supports a larger watershed [30]. The sudden drop in temperature to $21^{\circ} \mathrm{C}$ along with lower salinity in BR and CIRL suggest that the species of phytoplankton contributing to the bloom were more cold tolerant than salinity tolerant, as the $\mathrm{Chl} a$ concentrations decreased in the areas that had the largest decrease in salinity.

\subsection{Assessment of NDCI for the 2011 IRL Algal Bloom Mapping}

The MERIS NDCI algorithm was used to map and visually assess the 2011 algal bloom events for even in between the in-situ Chl $a$ and also track how the bloom ended. As MERIS RR data were released in near real time, it was possible to readily show the rapid changes in Chl $a$. The RR MERIS data have been used elsewhere: Studies conducted by Gower et al. [7,8] in the coastal waters of Vancouver, Canada found that small scale changes in Chl $a$ were lost but it remained a truthful depiction of the in-situ conditions. Moses et al. [24] also demonstrated the MERIS Chl $a$ algorithm was able to estimate the in-situ data without significant decreases in accuracy when the scenes up to two days before and after 
when the sampling date were used in order to increase the available samples. Satellite based rapid mapping of algal blooms will allow quick notification to health officials, residents and commercial interests of where the bloom may cause a threat.

With the ending of the ENVISAT mission in 2012, MERIS data has been made available and can be used to understand blooms or $\mathrm{Chl} a$ dynamics. Known historical blooms can be mapped along with the identification of any blooms that may have occurred between the monthly sampling periods, with or without calibration data. This will allow better understanding of conditions that may have contributed to the formation, growth, or decrease of the bloom which would lead to the ability to model seasonal blooms or future super blooms. For instance, the identification of periodic blooming after a rainfall could identify where to focus stormwater management efforts or identify unknown point and non-point sources. This work demonstrates how the IRL environmental managers would benefit greatly from the application of a remote sensing protocol for future blooms that would involve the data gathered by the Sentinel 3 satellite and application of the NDCI algorithm as well as the existing data the MERIS system gathered.

\section{Conclusions}

The MERIS Reduced Resolution (RR) data explained 79.8\% of the in-situ Chl $a$ measurements in the 2011 validation dataset. While there was a significant $(62.9 \pm 25 \%)$ underestimation of Chl $a$ using MERIS NDCI, the underestimation appears to be consistent across the data and mostly in the estimations of lower concentrations, suggesting that a qualitative or ratio analysis is still valid. The unexplained errors between the index estimated Chl $a$ and in-situ data could be accounted to lack of samples from the peak of the bloom and single sampling site per MERIS pixel. Using day before or after MERIS images, the number of sampling locations could be increased and also include a larger range of $\mathrm{Chl} a$ concentrations.

Analysis of the application of the NDCI processed MERIS data provided additional insights that the in-situ measurements were unable to record. During the month of October, the multiple MERIS images were able to show before and after conditions following a series of large rain and temperature changes. The analysis of these data suggests that the species responsible for the peak bloom were susceptible to the rapid changes in temperature and salinity.

This study demonstrated the value of the MERIS package in Chl $a$ assessment in a productive, Case 2 coastal lagoon system. Even with its limitations, the importance of its application for assessing algal bloom events at a landscape (or system) scale was demonstrated. Our findings suggest that the increasing salinity of the IRL may have led to additional large blooms, which were observed in the summers of 2012 and 2013.

\section{Acknowledgments}

This study was funded by the National Science Foundation, the National Geospatial-Intelligence Agency, and Bethune-Cookman University. The European Space Agency (ESA) provided MERIS RR Data Access. Additional GIS, weather, and water data were made available through the United States Geological Survey (USGS) and the National Oceanographic and Atmospheric Agency (NOAA). Special thanks go to the St. Johns River Water Management District for providing water quality data and GIS products, and especially to their staff (Margaret Lasi, Jan Miller, Lauren Hall, and Robert Chamberlain) who provided additional support and information. 


\section{Author Contributions}

Andrew Kamerosky obtained, processed, and analyzed the data used in this article. Hyun Jung Cho was the MS advisor for Andrew Kamerosky, she provided funds, guidance in the experimental design, and analysis of data, writing, and editing. Lori Morris provided expert insight to the Indian River Lagoon, assistance in data analysis, and editing.

\section{Conflicts of Interest}

The authors declare no conflict of interest.

\section{References}

1. Zimba, P.V.; Gitelson, A. Remote estimation of chlorophyll concentration in hyper-eutrophic aquatic systems: Model tuning and accuracy optimization. Aquaculture 2006, 256, 272-286.

2. Trees, C.C.; Clark, D.K.; Bidigare, R.R.; Ondrusek, M.E.; Mueller, J.L. Accessory pigments versus chlorophyll $a$ concentrations within the euphotic zone: A ubiquitous relationship. Limnol. Oceanogr. 2000, 45, 1130-1143.

3. Morel, A.; Prieur, L. Analysis of variations in ocean color. Limnol. Oceanogr. 1977, 22, 709-722.

4. Tedetti, M.; Charrière, B.; Bricaud, A.; Para, J.; Raimbault, P.; Sempéré, R. Distribution of normalized water-leaving radiances at UV and visible wave bands in relation with chlorophyll $a$ and colored detrital matter content in the southeast Pacific. J. Geophys. Res. 2010, 115, 2-10

5. Gitelson, A.A.; Merzlyak, M.N. Relationships between leaf chlorophyll content and spectral reflectance and algorithms for non-destructive chlorophyll assessment in higher plant leaves. J. Plant Physiol. 2003, 160, 271-282.

6. Gitelson, A.A.; Merzlyak, M.N.; Lichtenthaler, H.K. Detection of red edge position and chlorophyll content by reflectance measurements near $700 \mathrm{~nm}$. J. Plant Physiol. 1996, 148, 501-508.

7. Gower, J.; King, S.; Borstad, G.; Brown, L. Detection of intense plankton blooms using the MERIS optical imager on ENVISAT. Gayana 2004, 68, 246-251.

8. Gower, J.; King, S.; Borstad, G.; Brown, L. Detection of intense plankton blooms using the $709 \mathrm{~nm}$ band of the MERIS imaging spectrometer. Int. J. Remote Sens. 2005, 26, 2005-2012.

9. Miller, R.L.; Belz, M.; Castillo, C.D.; Trzaska, R. Determining CDOM absorption spectra in diverse coastal environments using a multiple pathlength, liquid core waveguide system. Cont. Shelf Res. 2002, 22, 1301-1310.

10. Novo, E.M.L.M.; Steffen, C.A.; Zuccari, F.B.C. Results of a laboratory experiment relating spectral reflectance to total suspended solids. Remote Sens. Environ. 1991, 36, 67-72.

11. Bricaud, A.; Babin, M.; Morel, A.; Claustre, H. Variability in the chlorophyll-specific absorption coefficients of natural phytoplankton: Analysis and parameterization. J. Geophys. Res. 1995, 100, 13321-13332.

12. Gilerson, A.A.; Zhou, J.; Gurlin, D.; Moses, W.; Ioannou, I.; Ahmed, S.A. Algorithms for remote estimation of chlorophyll- $a$ in coastal and inland waters using red and near infrared bands. Opt. Express 2010, 18, 24109-24125. 
13. Witte, W.G.; Whitlock, C.H.; Harriss, R.C.; Usry, J.W.; Poole, L.R.; Houghton, W.M.; Morris, W.D.; Gurganus, E.A. Influence of dissolved organic materials on turbid water optical properties and remote-sensing reflectance. J. Geophys. Res. 1982, 87, 441-446.

14. Tzortziou, M.; Herman, J.R.; Gallegos, C.L.; Neale, P.J.; Subramaniam, A.; Harding, L.W.; Ahmad, Z. Bio-optics of the Chesapeake Bay from measurements and radiative transfer closure. Estuar. Coast. Shelf Sci. 2006, 68, 348-362.

15. Gitelson, A.A.; Schalles, J.F.; Hladik, C.M. Remote chlorophyll $a$ retrieval in turbid, productive estuaries: Chesapeake Bay case study. Remote Sens. Environ. 2007, 109, 464-472.

16. Bargain, A.; Robin, M.; Men, E.L.; Huete, A.; Barillé, L. Spectral response of the seagrass Zostera noltii with different sediment backgrounds. Aquat. Bot. 2011, 98, 45-56

17. Hestir, E.L.; Khanna, S.; Andrew, M.E.; Santos, M.J.; Viers, J.H.; Greenberg, J.A.; Rajapakse, S.S.; Ustin, S.L. Identification of invasive vegetation using hyperspectral remote sensing in the California Delta ecosystem. Remote Sens. Environ. 2008, 112, 4034-4047.

18. Williams, M.R.; Filoso, S.; Longstaff, B.J.; Dennison, W.C. Long-term trends of water quality and biotic metrics in Chesapeake Bay: 1986 to 2008. Estuar. Coast. 2010, 33, 1279-1299.

19. European Space Agency MERIS Program Homepage. Available online: https://earth.esa.int/web/ guest/missions/esa-operational-eo-missions/envisat/instruments/meris (accessed on 9 January 2012).

20. Kalogirou, V.; Perez, J.R.; Arino, O. A first analysis on the Culture-MERIS products. Remote Sens. Lett. 2012, 4, 211-218.

21. Mishra, S.; Mishra, D.R. Normalized difference chlorophyll index: A novel model for remote estimation of chlorophyll $a$ concentration in turbid productive waters. Remote Sens. Environ. 2011, $117,394-406$

22. Gower, J.; King, S.; Goncalves, P. Global monitoring of plankton blooms using MERIS MCI. Int. J. Remote Sens. 2008, 29, 6209-6216.

23. Dall'Olmo, G.; Gitelson, A.A. Effect of bio-optical parameter variability and uncertainties in reflectance measurements on the remote estimation of chlorophyll- $a$ concentration in turbid productive waters: Modeling results. Appl. Opt. 2006, 45, 3577-3592.

24. Moses, W.J.; Gitelson, A.A.; Berdnikov, S.; Povazhnyy, V. Estimation of chlorophyll- $a$ concentration in case II waters using MODIS and MERIS data-Successes and challenges. Environ. Res. Lett. 2009, 44, doi:10.1088/1748-9326/4/4/045005.

25. Moses, W.J.; Gitelson, A.A.; Berdnikov, S.; Saprygin V.; Povazhnyi, V. Operational MERIS-based NIR-red algorithms for estimating chlorophyll $a$ concentrations in coastal waters-The Azov Sea case study. Remote Sens. Environ. 2012, 121, 118-124.

26. Phlips, E.J.; Badylak, S.; Christman, M.; Wolny, J.; Brame, J.; Garland, J.; Hall, L.; Hart, J.; Landsberg, J.; Lasi, M. Scales of temporal and spatial variability in the distribution of harmful algae species in the Indian River Lagoon, Florida, USA. Harmful Algae 2011, 10, 277-290.

27. Steward, J.S.; Virnstein, R.W.; Morris, L.J.; Lowe, E.F. Setting seagrass depth, coverage, and light targets for the Indian River Lagoon system, Florida. Estuar. Coast. 2005, 28, 923-935.

28. Steward, J.S.; Virnstein, R.W.; Lasi, M.A.; Morris, L.J.; Miller, J.D.; Hall, L.M.; Tweedale, W.A. The impacts of the 2004 hurricanes on hydrology, water quality, and seagrass in the central Indian River Lagoon, Florida. Estuar. Coast. 2006, 29, 954-965. 
29. St Johns River Water Management District SJRWMD 2012. Indian River Lagoon 2012 Superbloom Plan of Investigation. Available online: http://floridaswater.com/itsyourlagoon/initiative.html (accessed on 25 June 2012).

30. Steward, J.S.; Green, W.C. Setting load limits for nutrients and suspended solids based upon seagrass depth-limit targets. Estuar. Coast. 2007, 30, 657-670.

31. Mikkelsen, P.M.; Mikkelsen, P.S.; Karlen, D.J. Molluscan biodiversity in the Indian River Lagoon, Florida. Bull. Mar. Sci. 1995, 571, 94-127.

32. Raineault, N.A.; Arthur, C.T.; Miller, D.C. Mapping benthic habitats in Delaware Bay and the coastal Atlantic: Acoustic techniques provide greater coverage and high resolution in complex, shallow-water environments. Estuar. Coast. 2012, 35, 682-699.

33. Cerco, C.F.; Noel, M.R. Twenty-one-year simulation of chesapeake bay water quality using the CE-QUAL-ICM eutrophication model. J. Am. Water Resour. Assoc. 2013, 49, 1119-1133.

34. St Johns River Water Management District SJRWMD 2012. GIS Data Download Table. Available online: http://floridaswater.com/gisdevelopment/docs/themes.html (accessed on 25 June 2012).

35. United States Geological Survey USGS 2012. USGS Current Water Data for the Nation. Available online: http://waterdata.usgs.gov/nwis/rt (accessed on 25 June 2012).

36. National Aeronautics and Space Administration NASA 2012. Ocean Color Web. Available online: http://oceancolor.gsfc.nasa.gov/cms/ (accessed on 25 June 2012).

37. National Oceanic and Atmospheric Administration NOAA 2012. National Weather Service Weather Forecast Office Melbourne, FL. Available online: http://www.srh.noaa.gov/mlb/ (accessed on 25 June 2012).

38. National Oceanic and Atmospheric Administration NOAA 2012. National Climatic Data Center. Available online: http://www.ncdc.noaa.gov/ (accessed on 25 June 2012).

39. Phlips, E.J.; Badylak, S; Lasi, M; Chamberlain, R; Green, W; Hall, L; Hart, J; Lockwood, J; Miller, J; Morris, L; et al. From Red Tides to Green and Brown Tides: Bloom Dynamics in a Restricted Subtropical Lagoon under Shifting Climatic Conditions. Available online: http://link.springer.com/article/10.1007/s12237-014-9874-6?no-access=true $\quad$ (accessed on 6 December 2014).

40. Phlips, E.J.; Badylak, S.; Grosskopf, T. Factors affecting the abundance of phytoplankton in a restricted subtropical lagoon, the Indian River Lagoon, Florida, USA. Estuar. Coast. Shelf Sci. 2002, 55, 385-402.

41. Phlips, E.J.; Badylak, S.; Christman, M.; Lasi, M. Climatic trends and temporal patterns of phytoplankton composition, abundance, and succession in the Indian River lagoon, Florida, USA. Estuar. Coast. 2010, 33, 498-512.

(C) 2015 by the authors; licensee MDPI, Basel, Switzerland. This article is an open access article distributed under the terms and conditions of the Creative Commons Attribution license (http://creativecommons.org/licenses/by/4.0/). 